\title{
Management of 6 Months old Neglected Talus Neck Fracture: A Case Report with Review of Literature
}

\author{
Nagaraj Manju Moger ${ }^{\circledR 1}$, Pragadeeshwaran J ${ }^{2}$, Mosharaf Hossain Sarkar ${ }^{\circ}$, Pradeep Kumar Meena ${ }^{4} 4$ \\ ${ }^{1}$ Department of Orthopedics, All India Institute of Medical Sciences, Rishikesh, Uttarakhand, India, ${ }^{2}$ Department of Orthopedics, All India Institute of Medical Sciences, \\ Rishikesh, Uttarakhand, India, ${ }^{3}$ Department of Orthopedics, All India Institute of Medical Sciences, Rishikesh, Uttarakhand, India, ${ }^{4}$ Department of Orthopedics, All India \\ Institute of Medical Sciences, Rishikesh, Uttarakhand, India.
}

\section{Abstract}

Talus fractures are very rarely seen and account for approximately 1 percent of fractures around the foot and ankle Talar neck fractures are likely to damage the anastomotic ring, resulting in disruption of blood supply to the talar body which leads to significant problems in fracture healing and integrity. Approximately 39 percent of midfoot and ankle fractures could be missed during initial evaluation due to a lack of adequate radiological and clinical examination. Among these missed injuries approximately 50 percent are talus fractures. A 23 -year-old male patient came with complaints of pain over the left foot while walking for 6 months. He had a history of falls from 10 feet height 6 months back. He was conservatively managed in a local hospital without any proper diagnosis. He presented to us 6 months later with chronic, dull aching, continuous pain which aggravates while walking and standing. The diagnosis of the non-union fracture neck of talus was made after radiology and was managed by open reduction and internal fixation with cannulated cancellous screws along with ipsilateral iliac crest cancellous bone grafting. Lack of timely diagnosis escalates the vascular insult, delays timely intervention, and increases morbidity.

Keywords: Foot and Ankle, Fracture, Talus Fracture

Corresponding Author: Pradeep Kumar Meena, Department of Orthopedics, All India Institute of Medical Sciences, Rishikesh, Uttarakhand, India.

E-mail: dr.pradsms@gmail.com

Received: 22 April 2020

\section{Introduction}

Talus fractures are very rarely seen and account for approximately 1 percent of fractures around the foot and ankle. Most of the talus fractures occur in the talus neck which accounts for 50 percent of overall talus fractures. ${ }^{[1,2]}$ Even though it is rare, talus fractures have gained importance because of its typical vascularity. ${ }^{[3]}$

Talar neck fractures are likely to damage the anastomotic ring, resulting in disruption of blood supply to the talar body which leads to significant problems in fracture healing and integrity. This leads to osteonecrosis of the talar body which may lead to collapse also. Osteonecrosis is the most common and most serious complication following talar neck fractures. The second most common complication is subtalar arthritis. ${ }^{4]}$ Elgafy et al reported an association of 53.3 percent subtalar arthritis and 25 percent tibiotalar arthritis with talus fractures. ${ }^{[5]}$ Failure to prevent these complications will lead to chronic pain, disability, and multiple surgeries.
Early diagnosis and treatment are the utmost in preventing these complications. some studies show that talus fractures got missed easily during primary evaluation. Approximately 39 percent of midfoot and ankle fractures could be missed during initial evaluation due to a lack of adequate radiological and clinical examination. Among these missed injuries approximately 50 percent are talus fractures. ${ }^{[6-8]}$

Hence early diagnosis by using necessary modalities like computer tomography (CT), ultrasonography (USG), and magnetic resonance imaging (MRI) ensures a decrease in long term complications and morbidity of those patients. We present a case in which talus fracture got missed initially and was managed conservatively, later presenting as a non-union neck of the talus.

\section{Case Report}

A 23-year-old male patient came with complaints of pain over the left foot while walking for 6 months. He had a history of falls from 10 feet height 6 months back. He was conservatively 
managed in a local hospital without any proper diagnosis. He presented to us 6 months later with chronic, dull aching, continuous pain which aggravates while walking and standing. The patient was able to walk over the affected foot without any support. On examination, there was no tenderness over talus. Dorsiflexion and plantar flexion were full but supination and pronation were terminally painful. The distal neurovascular system was intact.

We did an x-ray of right ankle with the foot which showed a fracture line gap in neck of talus with sclerosed fracture ends and sclerosis over talar head [Figure 1]. The diagnosis of the non-union fracture neck of the talus was made.

Under spinal anesthesia, the patient was positioned lateral and tourniquet applied over mid-thigh. Tibialis anterior tendon, distal tibia, talus, and navicular palpated. Approximately 10 $\mathrm{cm}$ incision was given, starting $4 \mathrm{~cm}$ from the posterior edge of the medial malleolus to anteromedial border of navicular. Soft tissues and tendons carefully dissected. Medial malleolus osteotomy is done obliquely. The distal malleoli fragment is retracted along with its deltoid ligament attachment to expose the talus. Fracture ends identified and margins curetted till fresh bleed came. Fracture fragments held using reduction clamps and reduced. Ipsilateral iliac crest cancellous bone graft was harvested and put in the fracture gap. Fracture fixed using 2 cannulated cancellous (CC) screws. Osteotomy fixed using $2 \mathrm{CC}$ screws. Wound closed in layers and below-knee plaster of Paris slab was given. The patient was kept on non-weight-bearing mobilization for 4 weeks and was started partial weight bearing from $5^{\text {th }}$ week postoperatively. Full weight-bearing mobilization was started in the $3^{r d}$ month. Serial $\mathrm{x}$ rays were taken at 3 and 6 months postoperatively [Figure 2]. At the end of 6 months, the patient had complete union without any pain and restriction of movements and improved functional outcome.

\section{Discussion}

Talar neck fractures are treated on an urgent basis to decrease the risk of osteonecrosis since an immediate reduction can help to maintain any prevailing blood supply to the posterior talus. Heather et al suggest that if the reduction of talar neck has been achieved, then delay in fixation does not impact the occurrence of osteonecrosis. ${ }^{[9]}$ But even with timely management, talar neck fractures are associated with high complication rates in the long term which eventually leads to chronic pain and stiffness. $^{[10]}$

The pathophysiology of osteonecrosis is mainly due to the disruption of blood supply which causes the destruction of the organic component of bone. This leads to multiple microfractures and ending up in collapse. Talus being a weight-bearing bone and that too with a peculiar blood supply is more prone to osteonecrosis. ${ }^{[11]}$

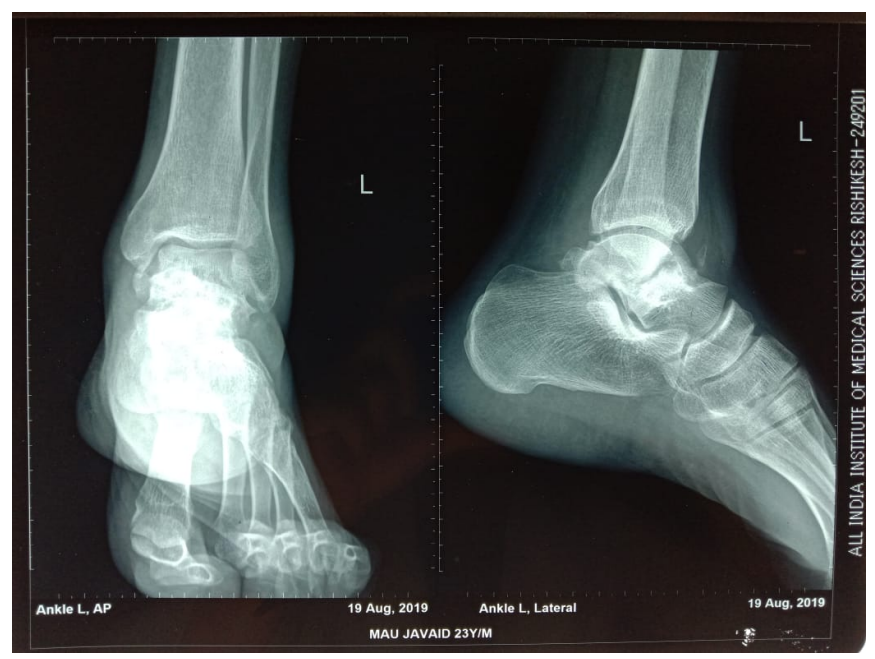

Figure 1: Preoperative X-ray showing the non-union gap at the fracture site with sclerotic fracture ends.

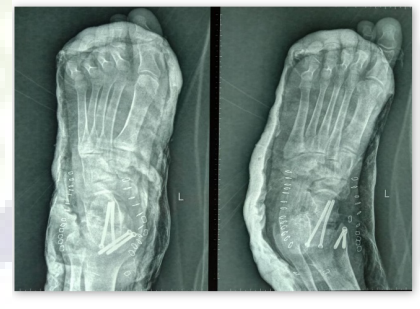

A

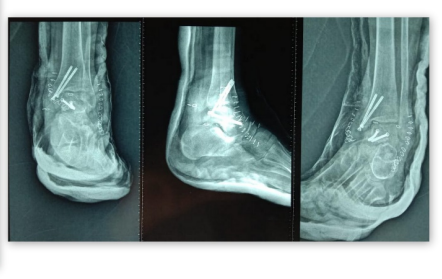

c

D
Figure 2: Immediate postoperative X-rayshowing graft in the non-union site with screw fixation of talus and medialmalleolus.

The extent of fracture displacement and soft tissue injury was shown to be direct causative factors of osteonecrosis in the literature. ${ }^{[12]}$ Our patient had missed diagnosis at the initial stage due to undisplaced fracture and had only swelling indicating minimal soft tissue component. But still, our patient developed osteonecrosis. Even with the improvement in surgical techniques and advanced fixation methods, early diagnosis and intervention are critical in preventing future complications.

Management of talar osteonecrosis varies from conservative to core decompression and bone grafting to arthrodesis and partial or total talar to total ankle replacement. The choice of management depends on the extent of necrosis and the staging of the disease. Berndt and Harty had classified 
talus osteonecrosis into 4 stages. ${ }^{[13]}$ Grafting varies from vascularised graft to non-vascularised free medial femoral condyle graft and iliac crest graft. We used non-vascular iliac crest cancellous graft in our patient and had a complete union at the end of 6 months without any symptoms.

\section{Conclusion}

Talar neck fractures may represent a small proportion of overall foot injuries but having an increased post-operative complication makes them more challenging to treat. Patients should be made aware of these complications and poor outcomes in the long run. Lack of timely diagnosis escalates the vascular insult, delays timely intervention, and increases morbidity.

\section{References}

1. Ahmad J, Raikin SM. Current Concepts Review: Talar Fractures. Foot Ankle Int. 2006;27(6):475-482. Available from: https://dx.doi.org/10.1177/107110070602700616.

2. Juliano PJ, Dabbah M, Harris TG. Talar neck fractures. Foot Ankle Clin. 2004;9(4):723-736. Available from: https://dx.doi. org/10.1016/j.fcl.2004.07.001.

3. Peterson L, Goldie IF. The Arterial Supply of the Talus: A Study on the Relationship to Experimental Talar Fractures. Acta Orthop Scand. 1975;46(6):1026-1034. Available from: https://dx.doi.org/10.3109/17453677508989293.

4. Dodd A, Lefaivre KA. Outcomes of Talar Neck Fractures. J Orthop Trauma. 2015;29(5):210-215. Available from: https: //dx.doi.org/10.1097/bot.0000000000000297.

5. Elgafy H, Ebraheim NA, Tile M, Stephen D, Kase J. Fractures of the talus: experience of two level 1 trauma centers. Foot Ankle Int. 2000;21(12):1023-9. Available from: https://dx.doi. org/10.1177/107110070002101208.

6. Wedmore I, Young S, Franklin J. Emergency Department Evaluation and Management of Foot and Ankle Pain. Em Med Clin North Am. 2015;33(2):363-396. Available from: https://dx.doi.org/10.1016/j.emc.2014.12.008.

7. Khadabadi NA, Putti BB, Jatti RS, Kale DR. Management of $1 \frac{1}{2}$ month old neglected talus neck fracture: A case report and review of literature. J Sci Soc. 2014;41(1):50-55. Available from: https://dx.doi.org/10.4103/0974-5009.126757.

8. Judd DB, Kim DH. Foot fractures frequently misdiagnosed as ankle sprains. Am Fam Physician. 2002;66(5):785-94.

9. Vallier HA, Nork SE, Barei DP, Benirschke SK, Sangeorzan BJ. Talar Neck Fractures: Results and Outcomes. J Bone Joint Surg Am. 2004;86(8):1616-1624. Available from: https: //dx.doi.org/10.2106/00004623-200408000-00003.

10. Bastos LR, Ferreira RC, Mercadante MT. Analysis of Clinical and Functional Outcome and Complications of Talar Neck Fractures. Revista Brasileira de Ortopedia (English Edition). 2010;45:362-374. Available from: https://dx.doi.org/10.1016/ s2255-4971(15)30382-7.

11. Pajenda G, Vécsei V, Reddy B, Heinz T. Treatment of talar neck fractures: Clinical results of 50 patients. J Foot Ankle Surg. 2000;39(6):365-375. Available from: https://dx.doi.org/ 10.1016/s1067-2516(00)80072-1.

12. Lindvall E, Haidukewych G, DiPasquale T, Herscovici D, Sanders R. Open Reduction and Stable Fixation of Isolated, Displaced Talar Neck and Body Fractures. J Bone Joint Surg. 2004;86(10):2229-2234. Available from: https://dx.doi.org/10.2106/00004623-200410000-00014. doi:10.2106/00004623-200410000-00014.

13. Berndt AL, M H. Transchondral fractures (osteochondritis dissecans) of the talus. J Bone Joint Surg Am. 1959;41(A):9881020 .

Copyright: (C) the author(s), 2020. It is an open-access article distributed under the terms of the Creative Commons Attribution License (CC BY 4.0), which permits authors to retain ownership of the copyright for their content, and allow anyone to download, reuse, reprint, modify, distribute and/or copy the content as long as the original authors and source are cited.

How to cite this article: Moger NM, Pragadeeshwaran J, Sarkar MH, Meena PK. Management of 6 Months old Neglected Talus Neck Fracture: A Case Report with Review of Literature. Asian J. Med. Res. 2020;9(2):11-13.

DOI: dx.doi.org/10.47009/ajmr.2020.9.2.OR3

Source of Support: Nil, Conflict of Interest: None declared. 